\title{
Euratom Research and Training in 2019: challenges, achievements and future perspectives ${ }^{\star}$
}

\author{
Roger Garbil ${ }^{1, *}$, Christophe Davies ${ }^{1}$, and Daniela Diaconu ${ }^{2}$ \\ ${ }^{1}$ European Commission (EC), DG Research and Innovation, Euratom Research, 21 rue du Champ de Mars, 1050 Brussels, \\ Belgium \\ ${ }^{2}$ Institute for Nuclear Research (ICN-RATEN), Campului 1, Mioveni 115400, Romania
}

Received: 18 September 2019 / Accepted: 1 October 2019

\begin{abstract}
The development and safe operation of nuclear installations in Europe is of vital importance for the future of nuclear energy. Helping to ensure the safe operation of nuclear power has always been one of the top priorities of Euratom Research Framework Programmes. With the incentives of Horizon 2020, further integration towards an EU/Euratom Research Area was achieved, better prioritisation at European and International levels based on updates of Research and Innovation agendas or deployment strategies, capitalisation of European Technology platforms and enhanced cooperation with International Organisations or Fora effectively happened. Evolutions towards European Joint Programmes together with EU/Euratom Member States, confirm that research and innovation programmes successfully benefit from a truly added value of a concerted European approach in nuclear safety research and training advocated by the European Commission and EU/Euratom Member States.
\end{abstract}

The 9th European Commission Conferences on EURATOM Research and Training in Safety of Reactor Systems and Radioactive Waste Management - FISA 2019 and EURADWASTE'19 [1,2] have been another major milestone on the EU/Euratom agenda. They gathered over 400 scientists from 200 organisations and 40 European countries and world-wide, being research and training organisations, academia, industry, technology platforms, European fora, European civil society, and International Organisations participating in EU/Euratom Framework Programmes. These two major scientific and policy events were organised jointly with the Romanian Presidency of the Council of the EU in 2019.

Their success lies in coherently summarising most activities of the main pillars of the EU/Euratom Fission research programmes. The following two sections of this special issue provide peer-reviewed papers, part 1) on Safety of reactor systems and part 2) on Radioactive waste management, and highlight major challenges, achievements and future perspectives of EU/Euratom Research and Training in 2019, and towards the next Horizon Europe research framework programme.

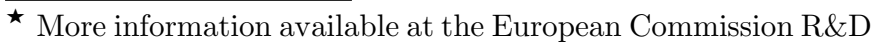
Information Service, CORDIS https://cordis.europa.eu/

* e-mail: roger.garbil@ec.europa.eu
}

\section{Part 1: Safety research and training of reactor systems}

Safety of nuclear installations [3-5] is constantly benefitting from research innovations in reactor performance, system reliability, advanced numerical simulation and modelling for reactor safety, applied to long-term operation (LTO) of current Generation II-III reactors. As identified within the European Technology platform SNETPNUGENIA Generation II-III water cooled reactor technology and technical research areas, LTO is an important challenge since most countries are now considering prolonging the lifetime of their power or research reactors from an originally foreseen 40 years' operation to usually 60 years. In order to safely extend the lifetime of these reactors or nuclear installations, both nuclear operators and regulators need to have, in addition to a skilled and well-trained workforce, robust and reliable research results. With the knowledge, and tools to assess and master any ageing and/or degradation process of components and/or structures, as well as methods and science-based guidelines for their validation, safe monitoring, management and operation will be ensured.

Nuclear safety [6-10] is also addressed through research on innovative Generation II-III fuel and materials, and the development of accident-tolerant fuels. Moreover, high performance research reactors have to overcome the 
challenging conversion from highly enriched to low enriched uranium fuels, to fulfil a worldwide nonproliferation effort. Safety assessments and severe accidents analysis, impact of external events on nuclear power plants, studies on mitigation of strategies, and probabilistic safety assessments were further supported. As a result, nuclear and radiological emergency management and preparedness within Europe and across the whole continent highly benefitted from a unified, shared and coordinated approach. As such, joint experimental research activities improve and strengthen any optimal use of shared resources, methodologies, tools, and collaboration at pan-European and international level. Strategic initiatives high on research and innovation agendas were supported, and lessons learned, as a response to the Fukushima Daiichi accident, reviews of technical and scientific improvements carried out, in the area of severe accident management, emergency preparedness and response.

Safety of advanced nuclear systems and fuel cycles [11-17] is supported through R\&D towards a new generation of more sustainable reactor technologies. Safety design and licensing of technologies are also identified as a high priority by the European Sustainable Nuclear Industrial Initiative of the Strategic Energy Technology Plan SET-Plan (SNETP-ESNII Generation IV fast reactors and closing the fuel cycle). Development of innovative fuels and materials benefits from advancements of EERA JPNM Joint Programme on Nuclear Materials for fission and fusion. Additionally, the entire nuclear fuel cycle is studied. From fuel fabrication to recycling strategies, partitioning and transmutation, to waste streams and high-level waste management, should help to meet, among others, the sustainable goals of minimisation of waste and better use of natural resources. Development of other applications for nuclear, such as the Nuclear Cogeneration Industrial Initiative with high temperature reactors (SNETP-NC2I, cogeneration of electricity and heat) is also presented. Cross-cutting nuclear data activities to the level needed by simulation codes to fulfil present requirements, for the safe and sustainable operation, development of existing and future fission and fusion reactors and nuclear fuel cycle facilities, are also presented.

Nuclear safety always remains a high priority and the European Union has an outstanding nuclear safety record. However, research must continue to maintaining the highest level of nuclear safety, security and safeguards through Education and training, research infrastructures and international cooperation [18-21]. The European nuclear sector is characterised by cutting edge technology and provides several hundred thousand people with highly skilled employments. To ensure our safety, both now and in the future, skilled people and well-equipped nuclear research facilities are of paramount importance. The availability of these resources is a crucial prerequisite for maintaining safety no matter what the future holds for the nuclear sector. Europe can retain its technological leadership only if Member States maintain a diverse and wellfunded nuclear R\&D capability, a fit-for-purpose system for the education and training of scientists and engineers, availability of state-of-the-art research infrastructures, and reinforced international cooperation in key strategic areas with leading third countries, bilaterally or multilaterally. EU/Euratom helps to stimulate joint funding from Member States and/or enterprises, joint programming and dialogue at EU level, cross-cutting fission/fusion/nonnuclear innovative initiatives and benefits are being capitalised, from Horizon 2020 towards Horizon Europe, from the increasing interaction between European technology platforms, EU stakeholder fora, as well as International Organisations such as OECD/NEA and IAEA.

\section{Part 2: Radioactive waste management}

International/EU/EURATOM Status in Radiation Protection, Safety of Reactor Systems and Radioactive Waste Management together with the Euratom Treaty provide the legal Framework to ensure a safe and sustainable use of peaceful nuclear energy across Europe and helps non-EU countries meet equally high standards of safety and radiation protection, safeguards and security. With legally binding Nuclear Safety Directive (2009/71/Euratom) and its latest amendment (2014/87/Euratom), EU nuclear stress tests, complemented with common safety approaches of the Western European Nuclear Regulators Association (WENRA) and the International Atomic Energy Agency (IAEA), the EU became the first major regional nuclear actor with a legally binding regulatory framework as regards to nuclear safety. Furthermore, this legal framework has been recently complemented by the Directive (2011/70/Euratom) that establishes a Community framework for the responsible and safe management of spent fuel and radioactive waste (both from fission and fusion systems), and the Directive (2013/59/Euratom) laying down basic safety standards for protection against the dangers arising from exposure to ionising radiation.

Directives on Nuclear Installations' Safety (Art.7), Nuclear Waste Management (Art.8), Basic Safety Standards (Ch.4) and IAEA Convention on Nuclear Safety, all emphasize that each MS shall take the appropriate steps to ensure that sufficient numbers of qualified staff with appropriate education, training and re-training are available for all safety-related activities in - or for each - nuclear installation throughout its life. 'Conclusions' were issued at: (a) 'EU Competitiveness Council in November 2008 encouraging Member States and the EC to establish a 'review of EU professional qualifications and skills' in the nuclear field; and (b) a 'Second Situation Report on EU E\&T in the Nuclear Energy Field' was published in 2014 by the European Human Resources Observatory in the Nuclear Energy Sector (EHRO-N, the latest created in 2009 by the European Nuclear Energy Forum (ENEF)). International/ $\mathrm{EU} /$ Euratom latest state of implementation of the main directives in radiation protection, safety of reactor systems and radioactive waste management, and role of the projects co-funded in the framework of EU/Euratom research and training programmes, challenges and research expectations are presented.

Predisposal and disposal technology developments, [22] is becoming a pillar domain of Euratom. It will require 
involvement of waste producers, technology developers and Research Entities (RE) in general. The Research Entities also play a role in the development of technologies for Geological Disposal. The role and contribution of Research Entities, in developing treatment processes and solutions for legacy and problematic waste, are illustrated, in particular from the perspective of smaller nuclear countries, pre-disposal and disposal technologies.

Radioactive waste source term and science for safety of geological disposal $[23,24]$ remain key challenges facing national programmes for high level waste and disposal of spent fuel, even though it is acknowledged that science and knowledge itself are very mature. A forward-looking view from a Member State with an advanced programme on geological disposal, as compared to many other EU/ Euratom Member States, is discussed. Challenges in science for the 'Safety Case', how to handle them for the benefit and synergies between different national programmes and categories of organisations, and how EU/ Euratom can further play its role in the future, is presented.

Networking of research communities, Joint Programming of national programmes and integration of Radioactive waste producers, [25-27] networking and support to collaborative research across different countries can be considered as the 'raison d'être' of the EU/Euratom programme. Views from three communities in the European Joint Programme EURAD officially launched last June 2019 (gathering Waste Management Organisations, Technical and Safety Organisations and Research Entities), from Central and Eastern Country's smaller and less-advanced programmes, on the benefits they see both for their own community and countries, in working together in a structured and forward looking manner. Knowledge Management, 'State of knowledge, Guidance on R\&D, and Training and mobility' activities within the Joint Programme is considered as the domain where the EU/Euratom role and support can bring most European added-value together with IAEA and OECD/NEA. Finally, how waste management, waste producers and technology developers will carry out research activities in a European framework and future joint activities are also presented.

All reviewed papers published in this special edition of EPJ-N are the result of a common effort of all partners involved. Thanks are due to many researchers, authors and the peer reviewers for the time and effort they spent to make this special issue possible. Our special thanks go to the peer reviewers listed here: Roger GARBIL (European Commission, DG RTD Euratom Research, BE), Christophe DAVIES (European Commission, DG RTD Euratom Research, BE), Daniela DIACONU (ICN-RATEN, $\mathrm{BE}$ ), Kirsten EPSKAMP (ENS, BE), Abderrahim AL MAZOUZI (EDF, FR), Stefano MONTI (IAEA), Giovanni BRUNA (Expert, FR), Teodora RETEGAN (CHALMERS, RO), Gérard COGNET (Expert, FR), Hans FORSSTROM (Expert, SE), Wilhelm BOLLINGERFEHR (BGE, DE), Piet ZUIDEMA (Zuidemaconsult, $\mathrm{CH}$ ), Jacques DELAY (ANDRA, FR). Furthermore, we are thankful to Gilles Moutiers and Anne Nicolas, Editors in
Chief of EPJ-N, for providing the opportunity to produce this special issue, to Mr Roger Garbil and Christophe Davies of the European Commission in Brussels for their active participation in the editorial process. Finally, Ms Daniela Diaconu of the Nuclear Research Centre RATENICN has to be gratefully acknowledged for making the FISA 2019 EURADWASTE '19 Conferences a reality, in Pitesti, in Romania, and another key milestone of the Euratom Research community.

The research PROJECTS leading to these results have received funding from the FP7/H2020 Euratom Research and Training Framework Programmes FP7/2007-2013 and H2020 2014-2018 under grant agreements $n^{\circ}$ [number].

\section{Appendix: List of PROJECT [Grant Agreement number] covered}

INCEFA-PLUS [662320], SOTERIA [661913], ATLASPLUS [754589], MEACTOS [755151], FP7-NUGENIAPLUS [604965], ADVISE [755500], NOMAD [755330], TEAMCABLES [755183], FP7-HARMONICS [269851], CORTEX [754316], McSAFE [755097], FP7-NURESAFE [323263], FP7-HPMC [295971], IL TROVATORE [740415], FP7-MULTIMETAL [295968], FP7-MATTER [269766], FP7-SCWR-FQT [269908], ESSANUF [671546], HERACLES-CP [661935], LEU-FOREVER [754378], IVMR [662157], SCO2-HeRo [662116], FP7-SAFEST [604771], FP7-CESAM [323264], FP7-ALISA [295421], NARSIS [755439], FP7-ASAMPSA-E [605001], FASTNET [662284], FP7-PREPARE [323287], ESFR-SMART [754501], ESNII+ [605172], SESAME [654935], SAMOFAR [661891], VINCO [662136], FP7-ALLIANCE [323295], FP7SILER [295485], FP7-SARGEN-IV [295446], FP7-JASMIN [295803], GENIORS [755171], FP7-SACSESS [323282], FP7-ASGARD [295825], MYRTE [662186], FP7-MARISA [605318], FP7-MAXSIMA [323312], FP7-SEARCH [295736], FP7-MAX [269565], FP7-FREYA [269665], FP7-ARCAS [249704], GEMMA [755269], INSPYRE [754329], M4F [755039], TRANSAT [754586], FP7-MATISSE [604862], FP7-PELGRIMM [295664], GEMINIPLUS [755478], FP7-NC2I-R [605167], FP7-CHANDA [605203], FP7-ERINDA [269499], FP7-EUFRAT [211499], ANNETTE [661910], ENEN-Plus [755576], BRILLIANT [662167], CORONA-II [662125], FP7-ENEN-RU-II [605149], FP7-ARCADIA [605116], FP7-NEWLANCER [295826], FP7-ECNET [269883], FP7-NUSHARE [335530], FP7-GENTLE [323304], CONCERT [662287], MEETCINCH [754972], FP7-ENETRAP-III [605159], FP7-EAGLE [604521], FP7-CINCH-II [605173], FP7-PETRUS-III [605265], FP7-TALISMAN [323300], FP7 and H2020 JHR Access rights [206300], INSIDER [755554], CHANCE [755371], THERAMIN [755480], FP7-DOPAS [323273], Modern2020 [662177], FP7-REDUPP (269903), DISCO [755443], FP7-CAST [604779], CEBAMA [662147], FP7-BELBAR [295487], BEACON [745942], MIND [661880], SITEX II [662152], JOPRAD [653951], EURAD (847593). 


\section{References}

1. R. Garbil, EPJ Nuclear Sci. Technol. 6, 46 (2020)

2. S. Abousahl et al., EPJ Nuclear Sci. Technol. 6, 45 (2020)

3. K.J. Mottershead et al., EPJ Nuclear Sci. Technol. 6, 44 (2020)

4. A. Schumm et al., EPJ Nuclear Sci. Technol. 6, 43 (2020)

5. C. Demazière et al., EPJ Nuclear Sci. Technol. 6, 42 (2020)

6. P. Agostini et al., EPJ Nuclear Sci. Technol. 6, 41 (2020)

7. S. Valance et al., EPJ Nuclear Sci. Technol. 6, 40 (2020)

8. J.P. Van Dorsselaere et al., EPJ Nuclear Sci. Technol. 6, 39 (2020)

9. E. Foerster et al., EPJ Nuclear Sci. Technol. 6, 38 (2020)

10. F. Rocchi et al., EPJ Nuclear Sci. Technol. 6, 37 (2020)

11. K. Mikityuk et al., EPJ Nuclear Sci. Technol. 6, 36 (2020)

12. S. Bourg et al., EPJ Nuclear Sci. Technol. 6, 35 (2020)

13. C. Ekberg et al., EPJ Nuclear Sci. Technol. 6, 34 (2020)
14. H. Aït Abderrahim et al., EPJ Nuclear Sci. Technol. 6, 33 (2020)

15. L. Malerba et al., EPJ Nuclear Sci. Technol. 6, 32 (2020)

16. G. Wrochna et al., EPJ Nuclear Sci. Technol. 6, 31 (2020)

17. E.M. Gonzalez et al., EPJ Nuclear Sci. Technol. 6, 30 (2020)

18. W. Ambrosini et al., EPJ Nuclear Sci. Technol. 6, 29 (2020)

19. M. Coeck et al., EPJ Nuclear Sci. Technol. 6, 28 (2020)

20. C. Fazio et al., R. Garbil, EPJ Nuclear Sci. Technol. 6, 27 (2020)

21. G. Bignan, J.-Y. Blanc, EPJ Nuclear Sci. Technol. 6, 26 (2020)

22. M. Nieminen et al., EPJ Nuclear Sci. Technol. 6, 25 (2020)

23. J. Andersson, EPJ Nuclear Sci. Technol. 6, 24 (2020)

24. P. Sellin et al., EPJ Nuclear Sci. Technol. 6, 23 (2020)

25. B. Nős, EPJ Nuclear Sci. Technol. 6, 22 (2020)

26. M. Garcia et al., EPJ Nuclear Sci. Technol. 6, 21 (2020)

27. M. Pieraccini, S. Granger, EPJ Nuclear Sci. Technol. 6, 20 (2020)

Cite this article as: Roger Garbil, Christophe Davies, Daniela Diaconu, Euratom Research and Training in 2019: challenges, achievements and future perspectives, EPJ Nuclear Sci. Technol. 6, E2 (2020) 